\title{
PARA LA ETIMOLOGÍA DE LA PALABRA JERIGONZA
}

Leyendo hace ya muchos años en mis clases de Latín Medieval la Vita S. Emiliani de San Braulio, obispo de Zaragoza, me llamó la atención el texto siguiente de la introducción:

«Superest quod et ultimum, quia schedulis haec uilibus malui tradere quam lento silentio tegere, ne ueritatis, longinqua praecedentium taciturnitas, derogaret posteris fidem. Sed et ut pauca his qui eloquentiam suam nituntur ostentare respondeam, nouerintque quod paruipenditur detractorum scurrilitas, quando, humilibus paruisque christianis eclesiastico iure non opponitur sequenda uana uerbositas, non humanae inquietudinis leuitas, non denique ostentationis uentositas, sed sobria modesta ponderataque ueritatis grauitas. Melius siquidem ut uera minus erudite quam ut ficta narrentur eloquenter. Quod in euangelia saluatoris perfacile intelligitur, quae populis sermone simplici praedicantur. Num ergo, pro mea imperitia, in sugillatione mitto uirorum prudentium eloquentiam? Minime. Sed leuitatem inprobo caducam; nam nec puto mihi succenseri posse, ob huius operis appetitum, honestos prudentes maturosque uiros, nequaquam ignaros in domo Domini offerri debere, ut cuique uires ministrant, usque ad caprarum pilos; quum, et ipsi si hinc discere uelint, ut praemissi, non solum illis non deerit materia sed minime poterint explicare cuncta. Quamobrem, disciplinarum saecularium studium, etsi ex parte attigi, omnino hic seruare contempsi ne, et intelligentiae difficultatem minus eruditis facerem et ex thericuntina lingua conturbarem Israelitica castraw'.

\footnotetext{
'Sancti Braulionis, Caesaraugustani Episcopi, Vila S. Emiliani. Edición Crftica por Luis Vázquez de Pargáa. Madrid, 1943, 5, págs. 10-12.
} 
Cuya traducción dice así: «Aún falta expresar el último motivo por que preferí confiar todo esto a pobres páginas que encubrirlo con lento silencio; y es que en estas verdades el prolongado callar de los antecesores no perjudicase al asentimiento que deben prestarles los que vengan después. Más para decirlo a los que se empeñan en hacer ostentación de su elocuencia, sepan que deben tenerse en poco las bufonadas de los detractores; pues a los cristianos humildes y pequeños no les propone el derecho eclesiástico que sigan la vana verbosidad, ni la ligereza de la inquietud humana, ni, finalmente, la vanagloria de mostrarse en público, sino la gravedad sobria, modesta y justa de la verdad. A fe que es mejor decir verdades con poca erudición que mentiras con mucha elocuencia: lo cual se entiende muy bien en los Evangelios del Salvador, que se predican el pueblo en estilo sencillo. ¿Será por eso que yo, llevado de mi impericia desprecie la elocuencia de los varones prudentes? De ningún modo; lo que repruebo es la inveterada ligereza de la gente mordaz. Pues no pienso que los varones honestos, prudentes y graves hayan de incomodarse conmigo por el poco gusto de esta obra, puesto que saben que en la casa del Señor debe ofrecerse aquello que cada uno puede; y que le es acepta hasta la ofrenda de las cosas de menos valor. Pero aún a las personas que de elocuencia se precian, si quisieran tratar este asunto, no sólo no les faltaría materia, como antes he dicho, sino que no podrían explicarlo todo. Por lo cual, aunque aprendí algo de las letras humanas, en manera alguna quise aprovecharme aquí de ellas, por no causar dificultad en el entenderlo a los menos instruidos, ni turbar los reales de Israel con el lenguaje de Jericón ${ }^{2}$.

Pero de este pasaje que doy en toda su extensión, aunque un poco larga, como marco para la mejor comprensión de lo que en el nos interesa, me fijé sobre todo en la expresión "Ihericuntina lingua» o lengua de Jericó, que me recordó, naturalmente, la palabra jeringonza, con su doble intención de lenguaje dificil de entender para los menos inctruidos y que podría producir perturbaciones o confusión en el campamento israelita.

Presumiendo que la frase final aludiria a algún episodio bíblico de los iaraelitas en su peregrinación por el desierto y ya en las cercanías de la ciudad de Jericó y del Jordán, consulté el caso a un buen escriturista, que me señaló concretamente este pasaje del libro de Josué, 6, 18: «Vos autem cavete, ne de his quae praecepta sunt quippiam contingatis et sitis

- Traduoción de fray Toribio Minguela, O. A. R. Editada en el libro San Millán de la Cegalla Trabajoe en colaboración, director, Juan B. Olarte. Madrid, 1976, pígs. 17-18. He moferido dar exta traducción, ya imṕresa y que me parece perfecta, en vez do otra mía. 
praevaricationis rei et omnia castra Israel sub peccato sint atque turbentur. ${ }^{3}$. Que dice aś en la traducción de Nácar-Colunga: «Guardáos bien de lo dado al anatema, no sea que, tomando algo de lo que así habéis consagrado, hagais anatema el campamento de Israel y traigáis sobre él ia confusión». Y en la de Bover-Cantera: «Vosotros, en verdad, guardáos bien de lo consagrado al exterminio, no sea que, llevados de la cociadi, cojáis de lo dado al anatema, atraigáis la maldición sobre el real de Israel y le acarrecis la desgracia* 4.

La frase de San Braulio: «ex Ihericuntina lingua turbentur Israelitica castra* tiene resonancias de la final también del versiculo citado: *et omnia castra Israel sub peccato sint atque turbentur", que subrayo en una y otra, y creo que por ellas me lo facilitó el recordado escriturista, como posiblemente aludido por el santo escritor. Claro está que el versículo se refiere a prevaricación de carácter moral y no meramente idiomáticoliterario, conforme al precedente, que anatematiza la ciudad de Jericó; mas no parece que haya otro pasaje más acorde o relacionado con la frase en cuestión y que habrá que suponer una traslación de lo moral a lo lingüístico en sentido metafórico $y$, a lo que parece, ya conocida o corriente como proverbial por entonces.

$Y$ sin duda la expresión aIhericuntina lingua» o lengua de Jericó tiene aquí la significación de lengua dificil de entender, ya naturalmente, como pódía serlo para los isaraelitas la de dicha ciudad, ya intencionalmente, como para los menos doctos o ignorantes una lengua demasiado alambicada. Pero estimo que cabe suponer además que junto al adjetivo se hubiera creado ya o se llegase a crear un sustantivo como * Ihericuntia que vendria a pasar casi normalmente a jerigonza, conservando la i protónica quizá por cultismo, aunque una vez sonorizada la $c$ pudiera romperse el enlace con la base de origen. Aparece esta en los

'El consultado fue don Manuel Rey Martínez, canónigo lectoral de la catedral de Santiago de Compostela, fallecido ya hace anos y a quien recuerdo con gratitud y afecto. En carta que conervo me confimaba su creencia de que $x$ alude al conocido episodio de Settim o Sittim (Númoros, 25), donde los israelitas fornicaron con mujeres moabitas y acrificaron a sus dioses, lo cual motivó la indignación de Dios contra ellos y el castigo. La lengua de aquella comarca en labios de tales mujeres apartó a los de lsrael del verdadero culto, introduciendo en su campamento confusión y mortandad. Esta lengua seria igual o poco menos a la de Jerico, ya que Settim estaba al norte de Moab y al eate del Jordán frente a dicha ciudad, oque era la principal de la comarca y por ello la lengua pudo ser llamada aIhericuntina lingua".

4 Sagreda Biblia. Versión directa de las lenguas originales por E. Nácar Fuater y A. Colunga, O. P., Madrid, B. A. C. MCMLXV, pág. 269, y Sagreda Biblia. Veraión crítica cobre los textos hebreo y griego por el Rvdo. P. J. M." Bover, S. I. y F. Cantera Burgos, B. A.C., I, Madrid, MCMXLVII, pag. 355. 
LXX como Hierichó o Jerichó, pero Estrabón, XVI, 2, 41, da Hiericóus o Hiericús, cuyo acusativo sería Hiericúnta o Hiericónta, posible base del supuesto sustantivo.

Pero lo que más me ha sorprendido al querer averiguar por otra parte la etimología de la voz en cuestión ha sido no haber hallado referencia alguna al pasaje de San Braulio, ni tampoco a su posible relación con el nombre de la ciudad de Jericó. Verdad es que en este punto he creído que podría confiar en el diccionario etimológico de $\mathrm{J}$. Corominas, dando desde luego por supuesto que habrá recogido en este caso y en general todo lo anterior en este campo, si bien elaborándolo a su modo para darnos sus soluciones.

Para Corominas jerigonza es sinónimo de jerga y por primera vez se lee en el Lazarillo (1554), pero a mediados del siglo XIII se halla girgonx. La voz jerga le parece un derivado retrógrado del occitano antiguo gergon, salido a su vez del francés antiguo jargon o gergon (dialectal gargon, primitivamente «gorjeo de los pájaros», de donde *habla incomprensible»), de la onomatopeya GARG- «hablar confusamente, tragar», etc., en relación con la garganta. El sinónimo jerigonza, medieval girgonz, le parece ser el mismo occitano gergons, caso recto de gergon (siglo XIII); pero que en España se confundió con girgonça «jacinto, piedra preciosa» (1250), que también venía del fr. jargonce, forma alterada de gagonce «jacinto" por influencia del fr. ant. jargon "piedra preciosa amarillorojiza" (del árabe zarqôn, cf. azarcón «minio, color anaranjado subido», del ár. zanqûn). A su vez jagonce procede en última instancia del gr. hyákinthos ${ }^{s}$.

Añade Corominas que se comprende fácilmente q'se el girgons occitano en el sentido de ajergaw se confundiera con la palabra girgonga, como aparece en varios textos medievales, o girgonu, ya que tanto la piedra preciosa como el habla jergal eran cosas rebuscadas y fuera del alcance del vulgo, y, por tanto, al designarlas podía tenerse la impresión de emplearla en sentido propio y metafórico, de donde la evolución: girgons, girgonx, girgonça, girigonça, gerigonça ${ }^{\circ}$. Pero el ingenioso razonamiento del insigne lexicógrafo me parece poco convincente en lo que se refiere al uso metafórico de un vocablo que designaba una piedra preciosa, por rara que fuera, por un modo más o menos rebuscado de hablar. Y que por vez primera aparece con este sentido, en la forma girgonx, en un pasaje del Alexandre, 1350c, sobre la Torre de Babel y la confusión de las lenguas.

'Diccionario Critico Etimológico de la Lengua Castellana, 11, s.v. jerga II, y Breve Diccionario Etimalogico de la Lengua Castellana, id.

- DCELC, pag. 2050. 
Creo que en todo caso es evidente que falta toda referencia o alusión al texto de San Braulio de Zaragoza, y que este texto debe ser tenido en cuenta al investigar el origen de la palabra que nos ocupa. Quizá sea necesario en cuanto sea también posible, buscarle otros enlaces con lo medieval y lo moderno, y de otra parte plantear de nuevo y de otro modo las relaciones entre jerigonza y jerga, y las palabras francesas y demás aducidas para explicarlo.

Abril.arid) M(oral.f.j() Laso Santiago de Compostela 